\title{
Review Article \\ Interaction of Herbs and Glibenclamide: A Review
}

\author{
Amita Rai, Cicy Eapen, and V. G. Prasanth \\ Department of Pharmaceutical Analysis, Grace College of Pharmacy, Kerala, Palakkad 678004, India \\ Correspondence should be addressed to Amita Rai, amisits@gmail.com
}

Received 30 April 2012; Accepted 30 May 2012

Academic Editors: A. Fernandez-Guasti and F. J. Miranda

Copyright (C) 2012 Amita Rai et al. This is an open access article distributed under the Creative Commons Attribution License, which permits unrestricted use, distribution, and reproduction in any medium, provided the original work is properly cited.

Herbs and herbal products are considered to be safer and people mix it often with the oral hypoglycemic agent in diabetes therapy. But numerous reports say that every combination of herbs and drugs is not safe. Some combinations may be beneficial and some may be harmful also. So before taking any herbal remedies with oral hypoglycemic agent, patient should consult physician. In this paper we are summarizing the reports available on the interaction of herbal remedies to one of the oral hypoglycemic agents (glibenclamide) and categorizing the effect of the combination is beneficial and harmful.

\section{Introduction}

Diabetes is a chronic disorder associated with high blood glucose level, either due to less production of insulin by the pancreas or due to inability of body cell to respond to the insulin produced. Based on this, there are two types of diabetes: Type I and Type II. Type I is also called as insulin-dependent diabetes mellitus (IDDM) which is produced mainly due to less production of insulin and type II as non-insulin-dependent diabetes mellitus (NIDDM) which is produced mainly due to inability of body cells to respond to the insulin produced. As per WHO August 2011 fact sheet $\mathrm{N}^{\circ} 312,346$ million people worldwide have diabetes and more than $80 \%$ of diabetes deaths occur in low- and middle-income countries. It is also projected that death due to this will be the double between 2005 and 2030 [1]. So the treatment strategy needs more attention. Another WHO 2002 report state that traditional medicine is being used by around $80 \%$ of population worldwide [2] So many people often combine the herbal remedies with oral hypoglycemic agent. They have mistaken that being natural all herbs and food are safe. But ample literatures suggest that natural does not mean it is completely safe. When the drug is taken orally it travels through the digestive system in mostly the same way as food and herbs taken. So, when it is mixed with herb, each can alter the others pharmacokinetic profile, that is, absorption, distribution, metabolism, and/or excretion. Some drugs interfere with the body's ability to absorb herbs. Similarly, some herbs and food can lessen or increase the impact of a drug [3]. The interaction can be beneficial or sometimes contraindicated also. A beneficial effect can be additive blood sugar lowering effect when glibenclamide is combined with certain herb but this effect can be harmful also when the sugar level goes down the normal level. This paper is an attempt to outline the interaction of herbal medicine to that of the antidiabetic drug glibenclamide. This study is focused on the interaction of herbs to that of glibenclamide. Herbs are discussed here with respect to their traditional uses, explored antidiabetic effect, pharmacological activity, and potential interaction with the glibenclamide.

Glibenclamide is one of the leading drugs from sulphonyl ureas category. It acts by inhibiting ATP-sensitive potassium channels in pancreatic beta cells which results in cell membrane depolarization opening voltage-dependent calcium channel. So the level of intracellular calcium in the beta cell increases and results in stimulation of insulin release [4].

\section{Herbal Remedies as Medicine}

Eighty percent of world population primarily relies on herbal formulation [5]. The use of herbal remedies for management of health is more prominent in the developing world population [2]. But there is a lacuna in understanding the efficacy and safety of herbal remedies. This is clear from the study in Trinidad, which revealed that medical practitioners 
in the public healthcare sector accept herbal remedies as a viable option but they lack sufficient knowledge on the uses and potential risks associated with this modality [6]. In developing countries, herbs have not got status of drug for the treatment of various ailment because of the problems associated with it. The concentrations of active component vary widely from one formulation to another. The problem associated with the development of herbal medicine includes presence of quite a lot of active ingredients, with fairly dissimilar pharmacological profiles, lack of quality control, lack of government regulations regarding safety and efficacy, insufficient clinical trials, and inadequate information on the adverse effects and drug-herbal interactions [7]. Some preparations may not contain any active ingredient and the most important evidence for efficacy of a particular product may be scanty and wholly unreliable. Most of the developed countries have not given status to the herbs as medicine. Like in United States of America and Canada, herbs are currently classified as botanical or dietary supplements [7]. Thus, the western-trained physicians are poorly experienced regarding herbal remedies and lack the knowledge on benefit and risk ratio of them. These types of conditions make a hostile environment for studying the interaction of herbs with drugs.

\section{Herbal-Glibenclamide Interaction}

3.1. Zingiber Officinale. It is commonly known as ginger. It is a herb and its rhizome (underground stem) is used as a spice and also as a medicine. It can be used in various forms either in fresh, dried, and powdered juice or oil. Its aqueous extract is being used traditionally in Jordan for antidiabetic activity. In vitro study in mouse myoblast and myotubes revealed that antidiabetic activity of ginger extract is due to its antioxidant activity, antiglycation activity, and its potential to express or transport Glut4 receptors from internal vesicles [8]. According to Al-Omaria et al. 2012, its interaction with glibenclamide was found to be promising in reducing blood glucose level in streptozotocin- (STZ-) induced diabetes [9]. The combinations of glibenclamide $(5 \mathrm{mg} / \mathrm{kg} \mathrm{BW})$ and ginger crude extract at doses (25 or $50 \mathrm{mg} / \mathrm{kgBW})$ significantly reduced the nonfasting blood glucose level 26.3\% $(P<0.001)$ and $25.1 \%(P<0.01)$, respectively, after $4.5 \mathrm{~h}$ which was better than the reduction by glibenclamide treatment alone $(7.9 \%)$. But their finding was in primitive level, and further study is required to optimize the ratio of combination with glibenclamide.

3.2. Cassia auriculata L. (Common Name: Tanner's Cassia). It is a common plant in Asia that has been widely used in traditional medicine as a cure for rheumatism, conjunctivitis, and diabetes. It is used in Ayurvedic medicine as "Avarai Panchaga Choornam" and also as the main constituent of Kalpa herbal teas. The leaf extract was found to have insulinogenic action in streptozotocin induced-diabetic rats [10]. The effect of flower of Cassia auriculata at a doses $0.45 \mathrm{~g} / \mathrm{kg}$ of body weight for 30 days in streptozotocininduced diabetic rats showed a comparable antidiabetic effect to glibenclamide. It may be a natural substitute because of its efficacy. But there is need for more detailed and systematic study to evaluate the combination effect [11].

3.3. Aloe vera. It is a species of succulent plant that probably originated in northern Africa. A single-blinded study in Thailand reported that $15 \mathrm{~mL}$ of aloe juice with glibenclamide significantly improved blood glucose level and lipid levels in the people with diabetes. In the same study, glibenclamide alone had not effectively controlled the diabetes in the people. This shows that the combination of herb with drug may have a beneficial and promising effect. But the rationale and validated combination is need of the time [12].

3.4. Ginkgo biloba. In a double-blind randomized trial on type 2 diabetic patients on oral antidiabetic therapy, administration of Ginkgo biloba extract (120 mg per day) for three months resulted in significant worsening of glucose tolerance. It did not impair glucose tolerance in the individual whose diabetes was controlled by diet. The extract increased hepatic clearance of insulin and oral hypoglycemic agents including glibenclamide. Thus it reduces insulin-mediated glucose metabolism and increases glucose level [13].

3.5. Pleurotus pulmonarius (Mushrooms). It showed potent and synergistic antihyperglycemic effect in combination with glibenclamide in alloxan-induced diabetic mice. The oral glucose tolerance test indicated the probability of combination of this plant extract with glibenclamide as an effective medication [14]. But the human trial is required in this regard.

3.6. Prickly Pear Cactus or Nopal (Opuntia ficus-indica (the Most Common Culinary Species), Opuntia fuliginosa (Purified Extract), Opuntia streptacantha, and Other Species). It is grown in North and South America and is traditionally used among Mexicans as food salads. Extracts of the plant seeds increased muscle and liver glycogen and reduced blood glucose levels in the streptozotocin-induced diabetic rats, demonstrating possibility of insulin-sensitizing effect [15]. There are few reports identify hypoglycemia as contraindication when taken concurrently with oral antidiabetic drugs [16]. So proper care is required while taking this herb in combination with the oral antidiabetic treatment.

3.7. Gymnema sylvestre. The active component is present in the leaves of the plant. Its active constituent gymnemic acid IV has shown a comparable potency to the glibenclamide after $6 \mathrm{~h}$ of administration, but has not changed the normal glucose level of mice [17]. In a review at Harvard Medical School of 108 clinical trials examining 36 herbs including Gymnema Sylvestre and 9 vitamin/mineral supplements, involving 4,565 patients with diabetes or impaired glucose tolerance conditions, researchers found that Gymnema sylvestre treatment had improved glucose control with very few adverse reactions [18]. But it was concluded that more research is required in this support. Several other studies where patients received Gymnema 
TABLE 1: Summary of herb-glibenclamide interaction.

\begin{tabular}{lll}
\hline Name of plant & Type of study & Interaction of glibenclamide \\
\hline $\begin{array}{l}\text { Zingiber officinale } \\
\text { Cassia auriculata }\end{array}$ & In STZ-induced diabetic rat & In STZ-induced diabetic rat \\
Aloe vera & $\begin{array}{l}\text { Placebo-controlled single blinded randomised study in } \\
\text { patients }\end{array}$ & Not documented \\
Ginkgo biloba & Double-blind randomised trial in patient & Beneficial and promising effect \\
$\begin{array}{l}\text { Pleurotus pulmonarius } \\
\text { Opuntia species }\end{array}$ & Alloxan-induced diabetic mice & Contraindication \\
Gymnema sylvestre & Trial in patients & Synergistic effect \\
$\begin{array}{l}\text { Trigonella foenum } \\
\text { graceum }\end{array}$ & STZ-induced diabetic rats & Contradictory results \\
Azadirachta indica & Alloxan-induced diabetic rabbits & Synergistic effect but showed hypoglycemia as \\
Momordica charantia & STZ-induced diabetic rats & adverse effect \\
Caffeine & Trial in type II diabetic patients & Synergistic effect \\
Allium Sativum & Alloxan-induced diabetic rats & No contraindication is reported \\
Coccinia indica & Alloxan-induced diabetic rats & Synergistic effect \\
Sesame oil & Mild to moderate diabetic patients & Contradictory reports about its beneficial effect in \\
\end{tabular}

sylvestre and glibenclamide separately showed the substantial efficacy of Gymnema sylvestre compared to glibenclamide [19]. Its combination with antidiabetic drug at $400 \mathrm{mg}$ over 18 months showed significant effect. But it also showed hypoglycemia in combination. So the combination needs to be evaluated with more trial and should be included in treatment plan under the observation of physician [20].

3.8. Trigonella foenum graceum (Fenugreek). In combination, it has improved glycemic control and decreased insulin resistance in the study of 25 patients with newly diagnosed type II diabetes mellitus when received $1 \mathrm{~g}$ of hydroalcoholic extract of fenugreek seeds daily for 2 months [20].

3.9. Azadirachta indica. It acts as a very effective antidiabetic drug and the effect is comparable with that of glibenclamide alone [21]. It needs to be evaluated in combination with glibenclamide.

3.10. Momordica charantia. It has shown hypoglycemic effect in streptozotocin-induced diabetic rats. Glibenclamide alone and the extract with its combination showed a significant reduction in the blood sugar level. The maximum hypoglycemic effect was observed by the high dose of glibenclamide with Momordica charantia fruit juice. It acts by increasing the renewal of $\beta$ cells in the pancreas or may permit the recovery of partially destroyed $\beta$ cells and stimulates pancreatic insulin secretion, which leads to significant increase in the plasma insulin level. Furthermore, it showed insulin-like properties and remarkably stimulates glycogen storage by the liver and improves peripheral glucose uptake $[22,23]$. But in this regard the clinical evidence is not available.
3.11. Caffeine. It is present in seeds, leaves, and fruits of some plants (Genus: Coffea). Some contradictory statements have been shown about caffeine and its effects on diabetes. Caffeine exaggerates the responses to standardized carbohydrate loads in habitual coffee drinkers who have type II diabetes [24]. However, different studies have concluded that coffee on everyday basis together with some changes in lifestyle habits helps to lower high blood sugar levels by increasing insulin sensitivity [24]. A randomized controlled trial in healthy volunteers found that consumption of coffee for 4 weeks increases fasting insulin concentrations compared with coffee abstinence [25]. It has advantage in decreasing insulin resistance. Still there is a need for more systematic study to conclude its role in combination therapy with glibenclamide.

3.12. Allium sativum. It is being used traditionally as spices in food. The benefits of a diabetic from taking garlic consist not only in lowering high blood sugar level, but also can provide a healthy blood circulation. It has comparable effect as that of Glibenclamide. It can be considered in combination but more trials are required [26].

3.13. Coccinia indica (Ivy Gourd). It grows wildly in many parts of the Indian subcontinent. It has been used from years to treat diabetes (madhumeha) in Ayurveda. The mechanism of action is not known, but the herb appears to have insulin-mimetic properties. In a double-blind, placebocontrolled, randomized trial, sixty newly diagnosed type 2 diabetic patients were recruited. These patients needed only dietary or lifestyle modifications (with fasting blood glucose in the range of $110-180 \mathrm{mg} / \mathrm{dL}$ ). One dropped out and 59 subjects completed the study, such that there were 30 subjects in the placebo group and 29 subjects in the experimental 
group. The subjects (33 male and 26 female) were aged between 35 and 60 years. It has significantly decreased the fasting and postprandial blood glucose levels of the experimental group at day 90 , by 16 and $18 \%$, respectively [27]. Interaction of this herb with glibenclamide has shown a significant hypoglycaemic, hypolipidemic, and antioxidant effect in diabetic rats and can be used safely in the treatment of diabetes [28]. It lacks the clinical evaluation for the combination.

3.14. Sesame Oil. Sesame oil (also known as gingelly oil or til oil) is an edible vegetable oil derived from sesame (Sesamum indicum) seeds. In addition of being used as cooking oil in South India, it is also used as a flavor enhancer in Chinese, Japanese, Korean, and to a lesser extent Southeast Asian cuisine. Sesame oil and glibenclamide combination therapy showed synergistic effect with glibenclamide in decreasing blood sugar level and provided a safe and effective option for the drug combination that may be very useful in clinical practice for the effective improvement of hyperglycemia [29].

\section{Conclusion}

Most of the studies conducted on patients were poorly designed including very less number of patients (Table 1). So there is a need for proper trial with large number of subjects under the care of medical practitioner. The results obtained from the trials should be included in the treatment plan of the diabetic patients. There is also a need for regulatory guideline regarding their uses. It is also required that western world should take initiative in systematic evaluation of the combination effect of herbal remedies and drugs. The western training should include the importance of herbal remedies so the practitioner trained for the uses of herbal medication will have clear idea about the uses of herbal remedies. The patients must be educated that before taking herbal medicine with glibenclamide, consult the doctors for their interaction as all herb-glibenclamide combination is not beneficial (Table 1).

\section{References}

[1] “WHO fact sheet no. 312," 2011, http://www.who.int/mediacentre/factsheets/fs312/en/\#.

[2] World Health Organization, WHO Traditional Medicine Strategy 2002-2005, WHO, Geneva, Switzerland, 2002.

[3] L. G. Miller, "Herbal medicinals: selected clinical considerations focusing on known or potential drug-herb interactions," Archives of Internal Medicine, vol. 158, no. 20, pp. 2200-2211, 1998.

[4] X. Serrano-Martín, G. Payares, and A. Mendoza-León, "Glibenclamide, a blocker of K+ATP channels, shows antileishmanial activity in experimental murine cutaneous leishmaniasis," Antimicrobial Agents and Chemotherapy, vol. 50, no. 12, pp. 4214-4216, 2006.

[5] W. M. Gesler, "Therapeutic landscapes: medical issues in light of the new cultural geography," Social Science and Medicine, vol. 34, no. 7, pp. 735-746, 1992.

[6] Y. N. Clement, A. F. Williams, K. Khan et al., "A gap between acceptance and knowledge of herbal remedies by physicians: the need for educational intervention," BMC Complementary and Alternative Medicine, vol. 5, article no. 20, 2005.

[7] R. B. Philp, "Herbal remedies: the good, the bad, and the ugly," Journal of Complementary and Integrative Medicine, vol. 1, pp. 1-11, 2004.

[8] M. P. Rani, M. S. Krishna, K. P. Padmakumari, K. G. Raghu, and A. Sundaresan, "Zingiber officinale extract exhibits antidiabetic potential via modulating glucose uptake, protein glycation and inhibiting adipocyte differentiation: an in vitro study," Journal of the Science of Food and Agriculture, vol. 92, no. 9, pp. 1948-1955, 2012.

[9] I. L. Al-Omaria, F. U. Afifib, and A. S. Salhaba, "Therapeutic effect and possible herb drug interactions of ginger (Zingiber officinale Roscoe, Zingiberaceae) crude extract with glibenclamide and insulin," Pharmacognosy Communications, vol. 2, no. 1, pp. 12-20, 2012.

[10] S. Gupta, S. B. Sharma, U. R. Singh, S. K. Bansal, and K. M. Prabhu, "Elucidation of mechanism of action of cassia auriculata leaf extract for its antidiabetic activity in streptozotocininduced diabetic rats," Journal of Medicinal Food, vol. 13, no. 3, pp. 528-534, 2010.

[11] L. Pari and M. Latha, "Effect of Cassia auriculata flowers on blood sugar levels, serum and tissue lipids in streptozotocin diabetic rats," Singapore Medical Journal, vol. 43, no. 12, pp. 617-621, 2002.

[12] N. Bunyapraphatsara, S. Yongchaiyudha, V. Rungpitarangsi, and O. Chokechaijaroenporn, "Antidiabetic activity of Aloe vera L. juice II. Clinical trial in diabetes mellitus patients in combination with glibenclamide," Phytomedicine, vol. 3, no. 3, pp. 245-248, 1996.

[13] G. B. Kudolo, "The effect of 3-month ingestion of Ginkgo biloba extract (EGb 761) on pancreatic $\beta$-cell function in response to glucose loading in individuals with non-insulindependent diabetes mellitus," Journal of Clinical Pharmacology, vol. 41, no. 6, pp. 600-611, 2001.

[14] S. L. Badole, N. M. Patel, P. A. Thakurdesai, and S. L. Bodhankar, "Interaction of aqueous extract of Pleurotus pulmonarius (Fr.) Quel-Champ. with glyburide in alloxan induced diabetic mice," Evidence-based Complementary and Alternative Medicine, vol. 5, no. 2, pp. 159-164, 2008.

[15] A. Trejo-González, G. Gabriel-Ortiz, A. M. Puebla-Pérez et al., "A purified extract from prickly pear cactus (Opuntia fuliginosa) controls experimentally induced diabetes in rats," Journal of Ethnopharmacology, vol. 55, no. 1, pp. 27-33, 1996.

[16] T. M. Bush, K. S. Rayburn, S. W. Holloway et al., "Adverse interactions between herbal and dietary substances and prescription medications: a clinical survey," Alternative Therapies in Health and Medicine, vol. 13, no. 2, pp. 30-35, 2007.

[17] Y. Sugihara, H. Nojima, H. Matsuda, T. Murakami, M. Yoshikawa, and I. Kimura, "Antihyperglycemic effects of gymnemic acid IV, a compound derived from Gymnema sylvestre leaves in streptozotocin-diabetic mice," Journal of Asian Natural Products Research, vol. 2, no. 4, pp. 321-327, 2000.

[18] G. Y. Yeh, D. M. Eisenberg, T. J. Kaptchuk, and R. S. Phillips, "Systematic review of herbs and dietary supplements for glycemic control in diabetes," Diabetes Care, vol. 26, no. 4, pp. 1277-1294, 2003.

[19] K. Baskaran, B. K. Ahamath, K. R. Shanmugasundaram, and E. R. B. Shanmugasundaram, "Antidiabetic effect of a leaf extract from Gymnema sylvestre in non-insulin-dependent diabetes mellitus patients," Journal of Ethnopharmacology, vol. 30, no. 3, pp. 295-305, 1990. 
[20] A. Gupta, R. Gupta, and B. Lal, "Effect of Trigonella foenumgraecum (Fenugreek) seeds on glycaemic control and Insulin resistance in type 2 Diabetes Mellitus : a double blind placebo controlled study," Journal of Association of Physicians of India, vol. 49, pp. 1057-1061, 2001.

[21] V. K. Lal, P. P. Gupta, P. Tripathi, and A. Pandey, "Interaction of Momordica charantia fruit juice with glibenclamide in streptozotocin induced diabetic rats," Pharmacology Online, vol. 3, pp. 853-857, 2011.

[22] M. W. Rahman, M. Mostofa, A. S. Sardar, M. R. Sultana, M. M. Haque, and M. E. Chaudhary, "Investigation of comparative hypoglycemic effect of neem (Azadiracta indica), Karala (Momordica charantea) and Nayantara (Canthranthus roseus) with Glibenclamide on Rat," International Journal of Pharmacology, vol. 1, no. 3, pp. 257-260, 2005.

[23] J. D. Lane, C. E. Barkauskas, R. S. Surwit, and M. N. Feinglos, "Caffeine impairs glucose metabolism in type 2 diabetes," Diabetes Care, vol. 27, no. 8, pp. 2047-2048, 2004.

[24] J. Ärnlöv, B. Vessby, and U. Risérus, "Coffee consumption and Insulin sensitivity," Journal of the American Medical Association, vol. 291, no. 10, pp. 1199-1201, 2004.

[25] R. M. Van Dam, W. J. Pasman, and P. Verhoef, "Effects of coffee consumption on fasting blood glucose and insulin concentrations: randomized controlled trials in healthy volunteers," Diabetes Care, vol. 27, no. 12, pp. 2990-2992, 2004.

[26] J. E. Eyo, J. C. Ozougwu, and P. C. Echi, "Hypoglicemic effct of Allium cepa, Allium sativum, and Zinziber officinal Aqueous extract of alloxan-induced diabetic rattus novergicus," Medical Journal of Islamic World Academy of Sciences, vol. 19, no. 3, pp. 121-126, 2011.

[27] R. Kuriyan, R. Rajendran, G. Bantwal, and A. V. Kurpad, "Effect of supplementation of Coccinia cordifolia extract on newly detected diabetic patients," Diabetes Care, vol. 31, no. 2, pp. 216-220, 2008.

[28] J. Eliza and P. T. Usha, "A Interaction of Coccinia indica with glibenclamide in alloxan induced diabetic rats," Indian Journal of Veterinary Research, vol. 20, no. 1, pp. 1-7, 2011.

[29] D. Sankar, A. Ali, G. Sambandam, and R. Rao, "Sesame oil exhibits synergistic effect with anti-diabetic medication in patients with type 2 diabetes mellitus," Clinical Nutrition, vol. 30, no. 3, pp. 351-358, 2011. 

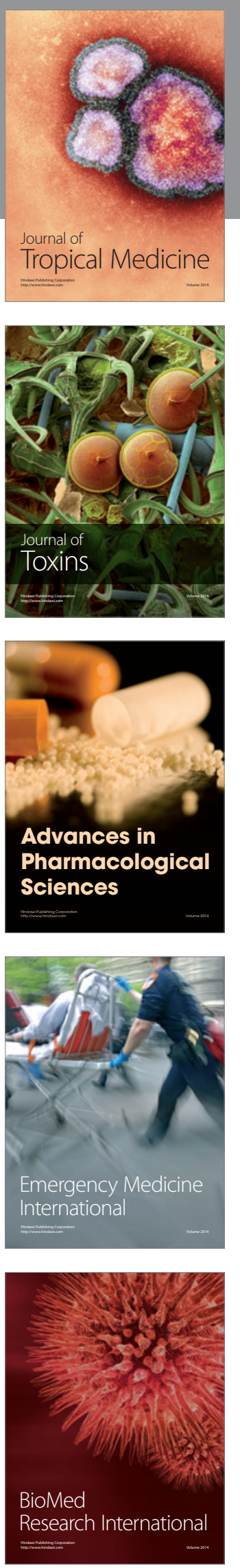
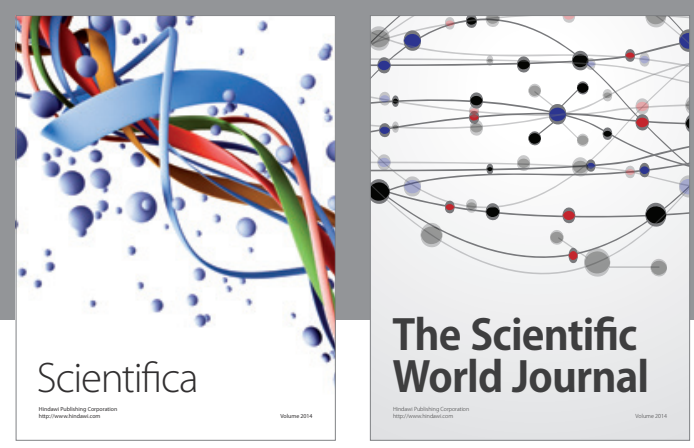

The Scientific World Journal
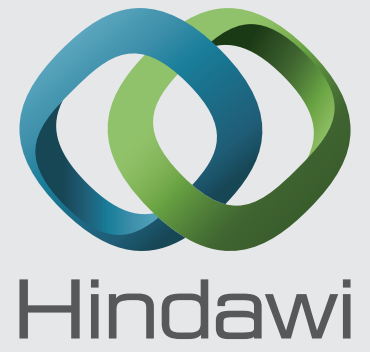

Submit your manuscripts at

http://www.hindawi.com
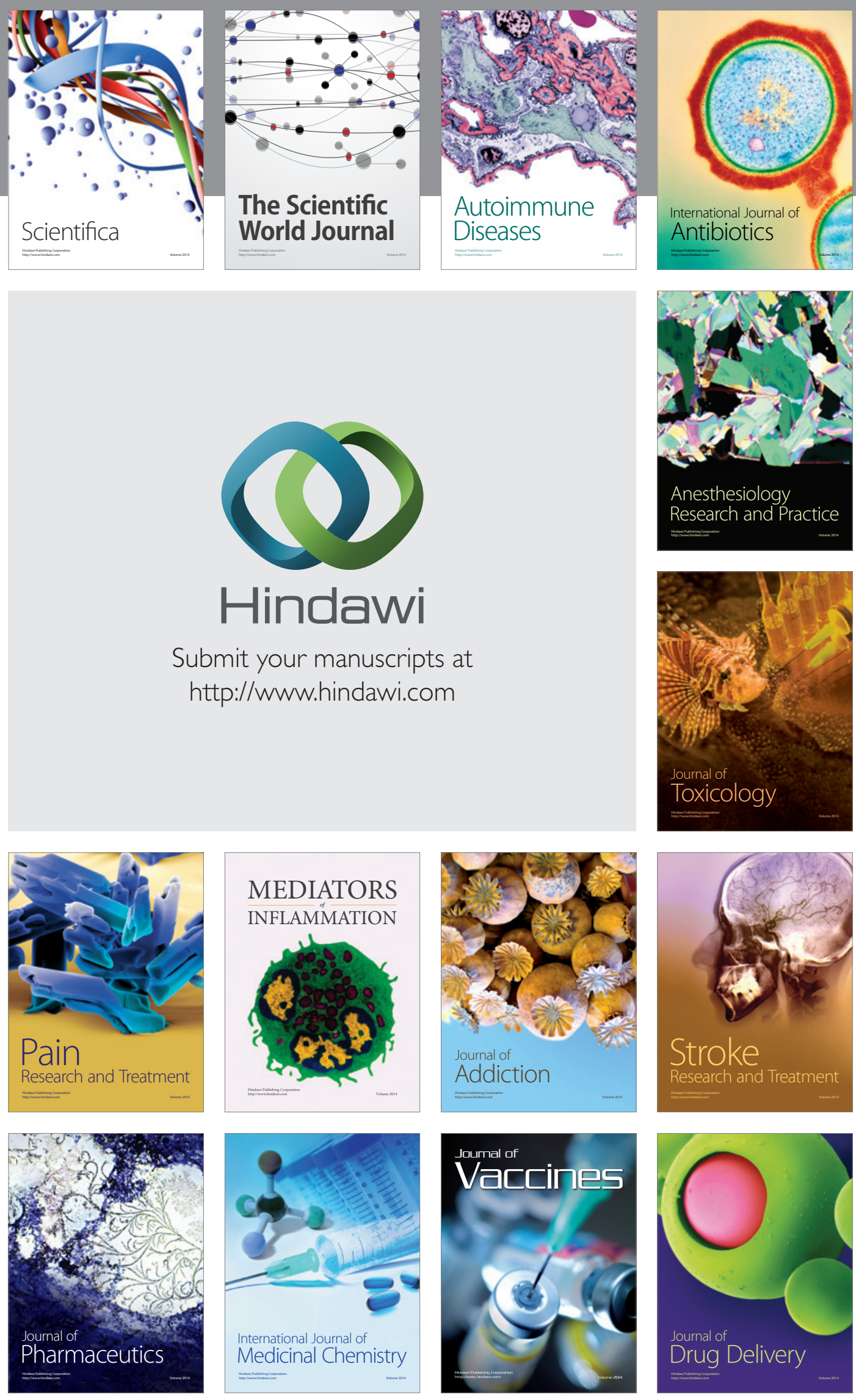